\section{Accidentes cerebrovasculares en estadounidenses de origen mexicano}

Entre la población general de los Estados Unidos de América, la causa principal de morbilidad y la tercera causa de muerte son los accidentes cerebrovasculares (ACV), que en gastos directos e indirectos imponen un gasto anual de US\$ 50000 millones. A pesar de que los estadounidenses de origen mexicano son el subgrupo de latinos mayoritario en los Estados Unidos, el más numeroso entre las minorías y el de más rápido crecimiento, no se dispone de datos sobre la porción de enfermedad cerebrovascular que representan. Por lo tanto, es difícil estimar el verdadero efecto de los $\mathrm{ACV}$ en la nación. Por cierto, hay factores de riesgo sociales y biológicos asociados a los ACV que afectan mucho más a esa población que a las personas de raza blanca no hispánicas, a saber: la prevalencia más alta de diabetes mellitus y, en muchos casos, una situación socioeconómica difícil y acceso limitado a una atención de salud de buena calidad. Solo con la presencia de esos factores puede predecirse que los ACV ocurrirán con mayor frecuencia en la comunidad mexicanoamericana, pero las estadísticas indican una mortalidad más alta por esa causa en los blancos no hispánicos, especialmente los de mayor edad. Sin embargo, es muy posible que en las estadísticas vitales se subestime la mortalidad por ACV de alguna colectividad, si el origen étnico no se codifica apropiadamente en las actas de defunción.

Teniendo en cuenta lo anterior, el equipo de investigadores de un proyecto denominado The Brain Attack Surveillance in Corpus Christi [La vigilancia del infarto cerebral en Corpus Christi] comparó la incidencia de ACV entre personas de ascendencia mexicana y personas de raza blanca no hispánicas, mayores de 44 años, por medio de un estudio poblacional. La comunidad estudiada comprende la ciudad de Corpus Christi, parte del condado de Nueces, al sureste del estado de Texas, donde reside una comunidad biétnica no migratoria. Los casos de ACV se determinaron por vigilancia tanto activa como pasiva, con la comprobación de neurólogos debidamente acreditados que ignoraban la etnia de los pacientes.

Desde enero de 2000 hasta diciembre de 2002 se registraron 2350 episodios de $\mathrm{ACV}$, definidos según los criterios ampliamente establecidos en el ámbito internacional. Dos terceras partes de los casos validados se seleccionaron al azar para administrarles una entrevista estructurada. Esta contenía preguntas sobre factores de riesgo, medicamentos en uso antes del episodio, acceso a la atención médica, raza y etnia. De los casos de infarto cerebral analizados, $53 \%$ ocurrieron en descendientes de mexicanos. La incidencia acumulada bruta fue de 168 por 10000 en mexicanoestadounidenses y de 136 por 10000 en blancos no hispánicos. En los primeros, la incidencia acumulada fue, de 45 a 59 años de edad: razón de riesgos $=2,04$, IC95\%: 1,55 a 2,69; de 60 a 74 años de edad: razón de riesgos $=1,58$, IC95\%: 1,31 a 1,91; de 75 o más años de edad: razón de riesgos =1,12, IC95\%: 0,94 a 1,32. La hemorragia intracerebral fue más común en los mexicanoestadounidenses (razón de riesgos ajustada por edad = 1,63, IC95\%: 1,24 a 2,16). Para la hemorragia subaracnoidea en el mismo grupo, la razón de riesgos ajustada por edad fue de 1,57 [IC95\%: 0,86 a 2,89]. Durante el período de estudio, hubo personas que sufrieron de dos a cuatro episodios de ACV. La población de ascendencia mexicana mostró una incidencia de infarto cerebral anémico y de hemorragia intracerebral notablemente mayor que la de blancos no hispánicos. El riesgo de sufrir un primer ACV entre los 45 y 59 años de edad fue casi el doble que en blancos no hispánicos. Sin embargo, la diferencia se acercó a cero cuando se compararon los integrantes de ambos grupos de 75 o más años de edad. En el estudio se encontró una interacción significativa entre edad y grupo étnico y la incidencia de infarto cerebral. Esa interacción no se observó en relación a la hemorragia subaracnoidea o intracerebral, si bien se notó una tendencia a esa interacción en la segunda.

Sin duda, la enfermedad cerebrovascular cobrará más y más importancia en la joven población mexicanoestadounidense a medida que esta envejezca. Hay varios aspectos no estudiados que deben abordarse en el futuro próximo. Por una parte, es necesario comparar la gravedad y el desenlace de los ACV entre grupos, en cuanto a la discapacidad y mortalidad resultantes. Asimismo, debe estudiarse el posible componente genético que tal vez produzca la disparidad. Por ejemplo, las malformaciones cavernosas, causa importante de la hemorragia intracerebral, se asocian a una mutación que aparece en grupos de ascendencia mexicana. De todos modos, es preciso concentrar más atención en 
prevenir los ACV en mexicanoestadounidenses y contar con las medidas terapéuticas que hagan falta para esa población. (Morgenstern LB, et al. Excess stroke in Mexican Americans compared with nonHispanic whites: The Brain Attack Surveillance in Corpus Christi Project. Am J Epidemiol. 2004; 160(4):376-383.)

\section{Una vacuna contra el virus de la inmunodeficiencia humana}

A pesar del éxito que ha tenido en los últimos años, el tratamiento antirretrovírico contra el virus de la inmunodeficiencia humana (VIH) adolece de imperfecciones. Su posible toxicidad, la dificultad para adherirse al régimen y otros problemas hacen que se sigan buscando formas más satisfactorias de tratar la infección por VIH. En ese sentido, la inmunización es una opción muy halagadora, pues podría no solo prevenir la infección sino aumentar la respuesta inmunitaria que controla la reproducción del virus. Se considera que una vacuna con una penetrancia de $25 \%$ puede ser tan eficaz como los tratamientos de rescate con antirretrovíricos de uso común, cuyo porcentaje de inhibición del ARN vírico es de $34 \%$ a las 12 semanas. Ninguna de las dos opciones es la óptima, pero ambas atenúan el progreso de la enfermedad y mejoran la supervivencia de los pacientes. Sin embargo, ya se han descartado diversas vacunas en estudio debido a que no producen una respuesta clínica adecuada. El estado actual de las vacunas plantea la pregunta de cuán eficaz tienen que ser para merecer mayor consideración. Su aceptabilidad tiene que examinarse a la luz de los estándares actuales de atención médica, los posibles resultados de la vacunación, su costo y el uso de los fondos destinados al cuidado de pacientes con VIH.

Puesto que los modelos simulados permiten evaluar los efectos de situaciones para las que se carece de datos, se usó un modelo computadorizado de infección crónica por VIH (con un recuento medio de células CD4 de $500 / \mathrm{mm}^{3}$ ) en una cohorte de 1 millón de presuntos pacientes para comparar la vacunación terapéutica con el tratamiento estándar sin vacunación. El objetivo del estudio fue establecer la eficacia relativa y los umbrales de eficacia en función del costo a ver si una vacuna terapéutica podría hacer una aportación valiosa a la atención de la infección por VIH.

Se analizaron los resultados de las pruebas clínicas de la vacuna en cuanto a la media de esperanza de vida, la esperanza de vida ajustada por calidad de vida, el costo y el tiempo sin necesidad de tratamiento antirretrovírico. Los pacientes hipotéticos entraron en el modelo uno a uno y pasaron por diversos estados de salud estratificados según el recuento de células CD4 y la carga vírica. Se introdujeron en el modelo datos tomados de la literatura. A cada paciente se le asignaron rasgos demográficos y clínicos según una distribución independiente predeterminada. Con cada muerte se admitió a otro participante. El modelo recogió las estadísticas individuales y colectivas sobre el tiempo que duró cada estado de salud, el tiempo de tratamiento y la causa de muerte.

El modelo incorporó seis valores de células CD4: (>500, 301-500, 201-300, 101-200, 51-100 y 50 células $/ \mathrm{mm}^{3} \mathrm{o}$ menos), también divididos por la concentración del ARN (>30 000, 10 001-30 000, 3 001-10 000, 501-3 000 y 500 copias/mL o menos). En cada estrato, que representa un valor de calidad de vida, los pacientes corrieron el riesgo de sucesos clínicos agudos incluso por toxicidad de los medicamentos. El modelo también incorporó infecciones oportunistas por Pneumocystis carinii, toxoplasmosis, el complejo Mycobacterium avis, infección micótica diseminada, citomegalovirus, infecciones bacterianas y otras complicaciones. Las medidas profilácticas se iniciaron según las normas vigentes en los Estados Unidos. En ausencia de tratamiento antirretrovírico, el punto de conversión al sida (según la concentración de ARN vírico) determinó el descenso de linfocitos CD4, mientras que el recuento de linfocitos CD4 absoluto determinó el riesgo de sucesos clínicos agudos. El modelo considera que el tratamiento antirretrovírico inhibe la carga vírica - como demuestran los ensayos clínicos-y la inhibición del virus hace aumentar el número de linfocitos CD4, lo que a su vez reduce el riesgo de infecciones oportunistas y detiene el progreso de la enfermedad hasta que la eficacia disminuye y el tratamiento falla. En este punto se inician otros tratamientos hasta que se agotan y cesa el proceso terapéutico.

El valor de la vacuna se calculó sobre la base de cuatro parámetros críticos: cambio del punto de conversión al sida, proporción de la cohorte beneficiada, duración del efecto y costo. La vacunación se dio por comenzada cuando el recuento de linfocitos CD4 fue de $500 / \mathrm{mm}^{3}$, valor cuya reducción dependió de la del ARN vírico. La vacuna, carente de toxicidad, se administró a razón de una inyección mensual por seis meses consecutivos, régimen conservador comparado con los ensayos reales. El recuento de CD4 se consideró estable durante esos seis meses y los efectos se manifestaron después de terminar la serie. La vacuna basal tuvo una magnitud de $0,5 \log$ y una penetrancia de $25 \%$ que dura tres años. El costo de la serie de seis inyecciones fue de US\$ 4000.

La vacuna con esas características aumentó la esperanza de vida ajustada en función de la calidad por 0,50 meses. Además, permitió retrasar el trata- 